\title{
Five-year results of lumbar disc prostheses in the SWISSspine registry
}

\author{
Emin Aghayev $\cdot$ Christian Etter $\cdot$ Christian Bärlocher $\cdot$ Friedrich Sgier $\cdot$ Philippe Otten • \\ Paul Heini - Oliver Hausmann · Gianluca Maestretti - Martin Baur · François Porchet • \\ Thomas M. Markwalder · Stefan Schären • Michal Neukamp · Christoph Röder
}

Received: 23 August 2013/Revised: 11 June 2014/ Accepted: 11 June 2014 / Published online: 20 June 2014 (c) Springer-Verlag Berlin Heidelberg 2014

\begin{abstract}
Purpose The Swiss Federal Office of Public Health demanded a nationwide HTA registry for lumbar total disc arthroplasty (TDA), to decide about its reimbursement. The goal of the SWISS spine registry is to generate evidence about the safety and efficiency of lumbar TDA.

Methods Two hundred forty-eight cases treated between 3-2005 and 6-2006, who were eligible for the 5-year follow-up were included in the study. Follow-up rates for 3-6 months, 1 , 2 and 5 years were 85.9, 77.0, 44.0 and $51.2 \%$, respectively. Outcome measures were back and leg pain, medication consumption, quality of life, intraoperative and postoperative complication and revision rates. Additionally, segmental mobility, ossification, adjacent and distant segment degeneration were analysed at the 5-year follow-up.
\end{abstract}

On behalf of the SWISSspine Registry Group.

E. Aghayev $(\bowtie) \cdot$ M. Neukamp · C. Röder

Institute for Evaluative Research in Medicine,

Stauffacherstrasse 78, 3014 Bern, Switzerland

e-mail: emin.aghayev@memcenter.unibe.ch

C. Etter

Hirslanden Clinic, Schänisweg, 5001 Aarau, Switzerland

C. Bärlocher

Stephanshorn Hospital, Brauerstrasse 95,

9016 St. Gallen, Switzerland

F. Sgier · O. Hausmann

St. Anna Clinic, St. Anna-Strasse 32, 6006 Lucerne, Switzerland

P. Otten

Rue Georges Jordil 4, 1700 Fribourg, Switzerland

P. Heini

Sonnenhof Clinic, Buchserstrasse 30, 3006 Bern, Switzerland
Results There was a significant, clinically relevant and lasting reduction of back (preop/postop 73/29 VAS points) and leg pain (preop/postop VAS 55/22) and a consequently decreased analgesics consumption and quality of life improvement (preop/postop 0.30/0.76 EQ-5D score points) until 5 years after surgery. The rates for intraoperative and early postoperative complications were 4.4 and $3.2 \%$, respectively. The overall complication rate during five postoperative years was $23.4 \%$, and the adjacent segment degeneration rate was $10.7 \%$. In $4.4 \%$ of patients, a revision surgery was performed. Cumulative survivorship probability for a revision/re-intervention-free 5-year postoperative course was $90.4 \%$. At the 5-year follow-up, the average range of motion of the mobile segments $(86.8 \%)$ was $9.7^{\circ}$. In $43.9 \%$ of patients, osteophytes at least potentially affecting the range of motion were seen.

\author{
G. Maestretti \\ Cantonal Hospital of Fribourg, 1708 Fribourg, Switzerland \\ M. Baur \\ Cantonal Hospital of Luzern, 6016 Lucerne, Switzerland \\ F. Porchet \\ Schulthess Clinic, Lengghalde 2, 8008 Zurich, Switzerland \\ T. M. Markwalder \\ Hirslanden Clinic, Salem-Spital, Schänzlistrasse 39, \\ 3013 Bern, Switzerland \\ S. Schären \\ University Hospital of Basel, Spitalstrasse 21, \\ 4031 Basel, Switzerland
}


Conclusions Lumbar TDA appeared as efficient in longterm pain alleviation, consequent reduction of pain medication consumption and improvement of quality of life. The procedure also appeared sufficiently safe, but surgeons have to be aware of a list of potential adverse events. The outcome is stable over the 5-year postoperative period. The vast majority of treated segments remained mobile after 5 years, although almost half of patients showed osteophytes.

Keywords SWISSspine - TDA - Disc arthroplasty · Lumbar disc prosthesis · Long-term follow-up

\section{Introduction}

Although surgical fusion of the painful degenerated lumbar intervertebral disc has always been a matter of debate, it has become a gold standard procedure for all cases that lack an alternative treatment [1]. At the end of the 1990s, total disc arthroplasty (TDA) was introduced as a motionpreserving treatment method. While the motion-preserving principle of TDA is regarded as a strict antithesis of fusion, the short-term and first long-term evidence from investigation device exemption studies show mostly equivalent outcomes after lumbar TDA and anterior lumbar interbody fusion (ALIF) [2,3] with some differences in favour of TDA like, e.g., improved physical function and earlier return to work [4-6]. The recently published 5-year followup of a Swedish randomized clinical trial (RCT) with a very high follow-up rate showed significantly better outcomes in almost all clinical and functional outcomes for TDA patients in comparison with posterior spinal fusion in highly selected patients [7]. However, ALIF and not posterior fusion is regarded as the most appropriate TDA comparator. Available long-term single-arm studies are mostly of the monocentric type and report on only one-disc prosthesis model such as Maverick, AcroFlex, Prodisc-L or Charité [8-12]. The Swedish RCT was also monocentric [7]. Two long-term RCTs with a single disc model by Guyer et al. [3] and by Zigler et al. [2] collected data from multiple sites.

Long-term follow-up data are particularly expected to answer questions of complication and revision rates, probability of survivorship and adjacent segment degeneration. The data on these outcomes are still sparse and hinder acceptance of lumbar TDA on a larger scale.

Due to increased use, reports on high complication rates, and a general uncertainty regarding treatment outcomes, a governmentally mandated Swiss national registry for disc arthroplasty and some other spinal implants were established in March 2005. Short-term outcomes of lumbar TDA from the so-called SWISSspine registry were already reported [13-16]. The next step in the technology assessment was the analysis of the 5-year follow-up results, which are presented in the current study.

\section{Materials and methods}

The SWISSspine registry

The detailed setup of the registry was already reported [13]. The nationwide registry is ongoing since March 2005 and documents the following data: surgeon-based intervention and follow-up forms, patient-based preoperative comorbidity form as well as pre- and postoperative North American Spine Society outcome assessment instrument for the lumbar spine (NASS) and EuroQoL-5D [13]. Additionally, an informed consent form is signed by each patient. The registry runs on the generic registry platform MEMdoc of the Institute for Evaluative Research in Medicine at the University of Bern [17]. Since the registry is a governmentally mandated quality and technology assessment project, no approval of the local ethics committees was needed.

\section{Sample characteristics}

Five-year follow-ups were initiated in 2011 and included 248 eligible patients, who were treated between March 1st 2005 and July 1 st $2006.22 .8 \%$ of those patients were treated on two levels. $54.8 \%$ were female. Females were on average 41.1 years old (SD 8.4 years; range 19-65 years); the male mean age was 43.6 years (SD 7.8 years; range 20-64 years). Figure 1 demonstrates proportions of different comorbidities at the time of surgery.

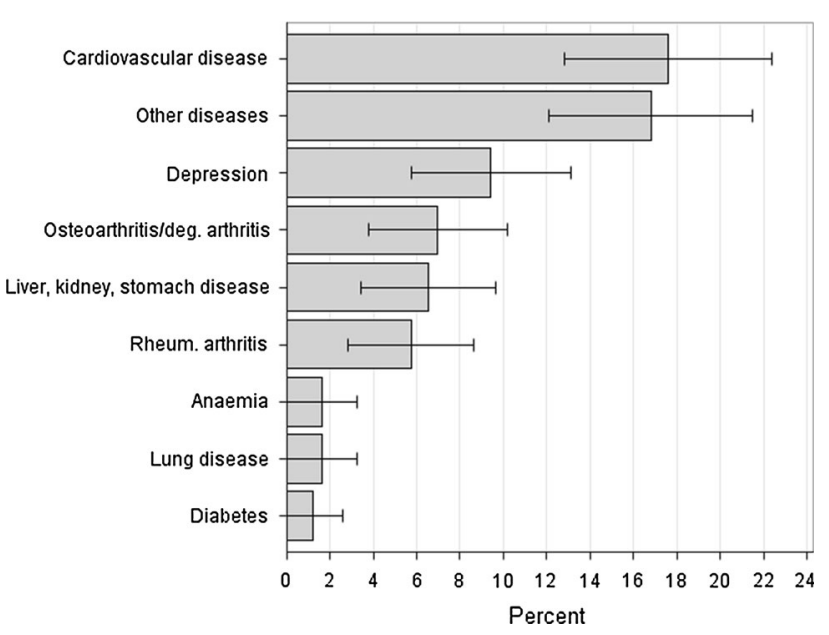

Fig. 1 Comorbidities (\%) 
The following five devices were implanted in the considered time period and included in the current report (in alphabetic order): Activ L, B. Braun ${ }^{\circledR}$; Charité, DePuy ${ }^{\circledR}$; Dynardi, Zimmer ${ }^{\circledR}$; Maverick, Medtronic ${ }^{\circledR}$; ProDisc-L, Synthes ${ }^{\circledR}$.

The analyses focused on the 3-6 month, 1-, 2- and 5-year follow-ups. Surgeon-based follow-up rates for the given time points were 85.9, 77.0, 44.0 and $51.2 \%$, respectively. Despite trying to contact every patient for the 5-year follow-up, $48.8 \%$ of patients were lost to follow-up due to different reasons: unwillingness to participate $(n=16)$, revision surgery on the index level (included in the revision rate) $(n=10)$, patient moved away $(n=6)$, surgeon moved away $(n=4)$, follow-up appointment could not be set up yet $(n=2)$, patient death due to reasons unrelated to the TDA surgery $(n=1)$, patient in prison $(n=1)$, not specified $(n=81)$. Notably, 54 of 81 patients with no specified reason $(54 / 248=21.8 \%)$ were already lost 1 year after surgery, and 67 of 81 patients were lost 2 years after surgery $(67 / 248=27.0 \%)$.

In total, 829 follow-ups were performed during the five postoperative years, which resulted in an average 3.3 follow-ups per patient.

\section{Outcome measures}

The following outcomes were assessed:

1. Back and leg pain levels (VAS on NASS form).

2. Pain medication (based on pre- and postoperative surgeon forms: none, NSAIDs, weak opiates, strong opiates).

3. Quality of life [EuroQoL-5D, score ranging from -0.6 (worst possible quality of life) to 1 (best possible quality of life)].

4. Complication and revision rates (based on peri- and postoperative surgeon forms).

5. Heterotopic ossification (HO) [only at the 5-year time point: (a) X-ray based surgeon assessment with an answer for ossification yes/no, (b) X-ray based assessment of an independent assessor using McAfee classification] [18]. Category 0 -no HO present; category I- HO present in islands of bone within soft tissue, but not influencing the range of motion of the vertebral motion segment; category II- $\mathrm{HO}$ possibly affecting segmental range of motion and/or HO present between the two planes formed by the vertebral endplates; category III-range of motion of the vertebral endplates is blocked by the formation of $\mathrm{HO}$ and/or postoperative osteophytes on flexion-extension or lateral bending radiographs; category $\mathrm{IV}-\mathrm{HO}$ is causing inadvertent arthrodesis by bridging trabecular bone between adjacent endplates and $<3^{\circ}$ of motion on lateral flexion-extension radiographs [18]. To compare the surgeon and independent assessors' ratings, McAfee categories 0-II were grouped as no ossification and categories III and IV as ossification.

6. Segmental mobility (only at the 5-year time point: sagittal X-ray measurements in flexion and extension). The involved surgeons indicated whether the treated level was mobile (yes/no). Subsequently, an independent assessor measured the ROM on functional X-rays. Segments with ROM $<2^{\circ}$ were considered as immobile. The data for heterotopic ossifications and segmental mobility were available for $68.5 \%(n=87)$ of the patients, who were examined at 5-year follow-ups and also underwent an X-ray examination $(n=127)$.

7. Adjacent segment degeneration (ASD). The involved surgeons indicated whether a progressing degeneration of cranial, caudal or both adjacent segments as well as of cranial, caudal or both distant segments had taken place. The data on adjacent segment degeneration were available for $81.1 \%(n=103)$ of the patients and on distant segment degeneration for $74.8 \%(n=95)$ of the patients, who were examined at 5-year followup $(n=127)$. The missing entries were not regarded as absence of degeneration, but excluded from the calculations of rates.

Statistical analysis

Wilcoxon's rank-sum test was used for comparisons between baseline and follow-up continuous variables such as pain on VAS. When comparing proportions, the Chisquare test was used. Associations between follow-up interval and proportion of different medications were tested using the Cochran-Armitage Trend test.

Kaplan-Meier survival analysis was performed with the first revision of any type as the end point. Patients were censored at their last available follow-up.

$\alpha$ was set to 0.05 throughout the study. All statistical analyses were conducted using SAS 9.3 (SAS Institute, Inc., Cary, NC, USA).

\section{Results}

The average follow-up time for the 5-year follow-ups was 5.55 years (95\% confidence interval 5.46-5.64 years; range $4.10-6.50$ years).

Pain levels and medication

There was a significant $(p<0.001)$ and long-lasting back and leg pain relief from 72 and 55 points preoperative to 28 
Fig. 2 The course of back and leg pain over 6.5 years with the $95 \%$ confidence intervals. All available follow-ups per patient were considered

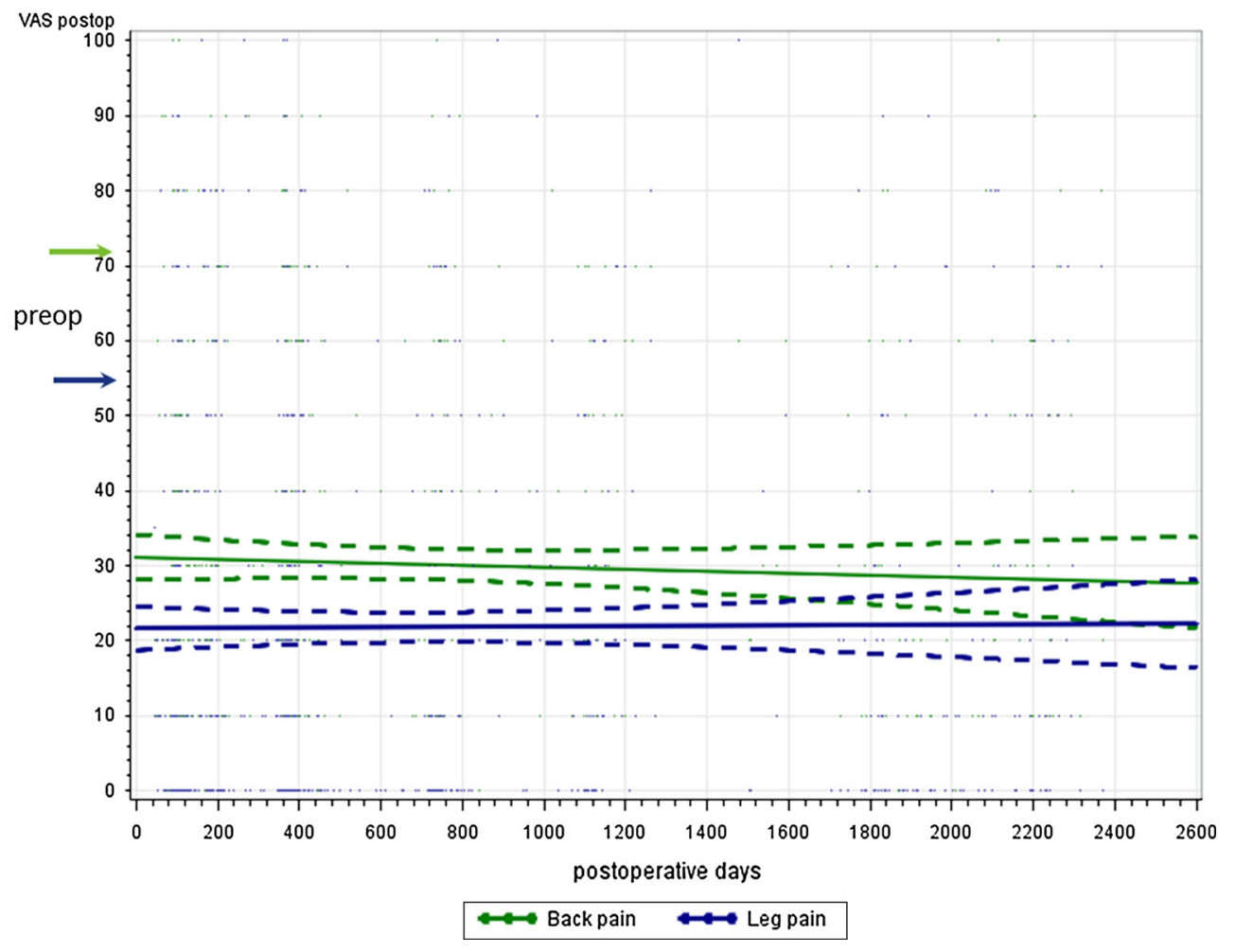

motion (ROM) was between $0^{\circ}$ and $2^{\circ}$. The average range of motion of the remaining mobile segments $(87.0 \%)$ was $9.8^{\circ}$ (range $2^{\circ}-25^{\circ}$; SD $5.7^{\circ}$ ), whereas in $13.0 \%$ ROM was between $2^{\circ}$ and $3^{\circ}$. In patients treated on two levels, the caudal segments were on average $2.5^{\circ}$ less mobile than the cranial ones $\left(7.8^{\circ}\right.$ vs. $\left.10.3^{\circ} ; p=0.043\right)$. Regarding osteophytes, $13.2 \%$ of segments were classified as McAfee grade $0,43.0 \%$ as grade I, $27.2 \%$ as grade II, $16.7 \%$ as grade III and none as grade IV.

\section{Complication and revision rates}

Analysis of complications and revisions by treated level is shown in Table 1.

During surgery, a total of 11 complications in 11 patients occurred $(4.4 \%)$. In particular, there were five vessel injuries, two vertebral fractures, two dura lesions, one subsidence of the prosthesis and one ureter lesion. The rate of intraoperative complications was higher in bisegmental $(7.1 \%)$ than in monosegmental patients $(3.6 \%)$.

Postoperatively, in eight patients $(3.2 \%)$ a new radiculopathy between L3 and S1 was diagnosed. The new radiculopathy was more frequent in monosegmental $(3.6 \%)$ than in bisegmental patients $(1.8 \%)$. In four patients with the new radiculopathy and in six other patients $(10 / 248=4.0 \%)$ a re-intervention was performed. The re-intervention rate in bisegmental patients $(8.9 \%)$ was higher than in monosegmental patients 
Fig. 3 The course of EQ-5D score-based quality of life over 6.5 years with the $95 \%$ confidence intervals. All available follow-ups per patient were considered

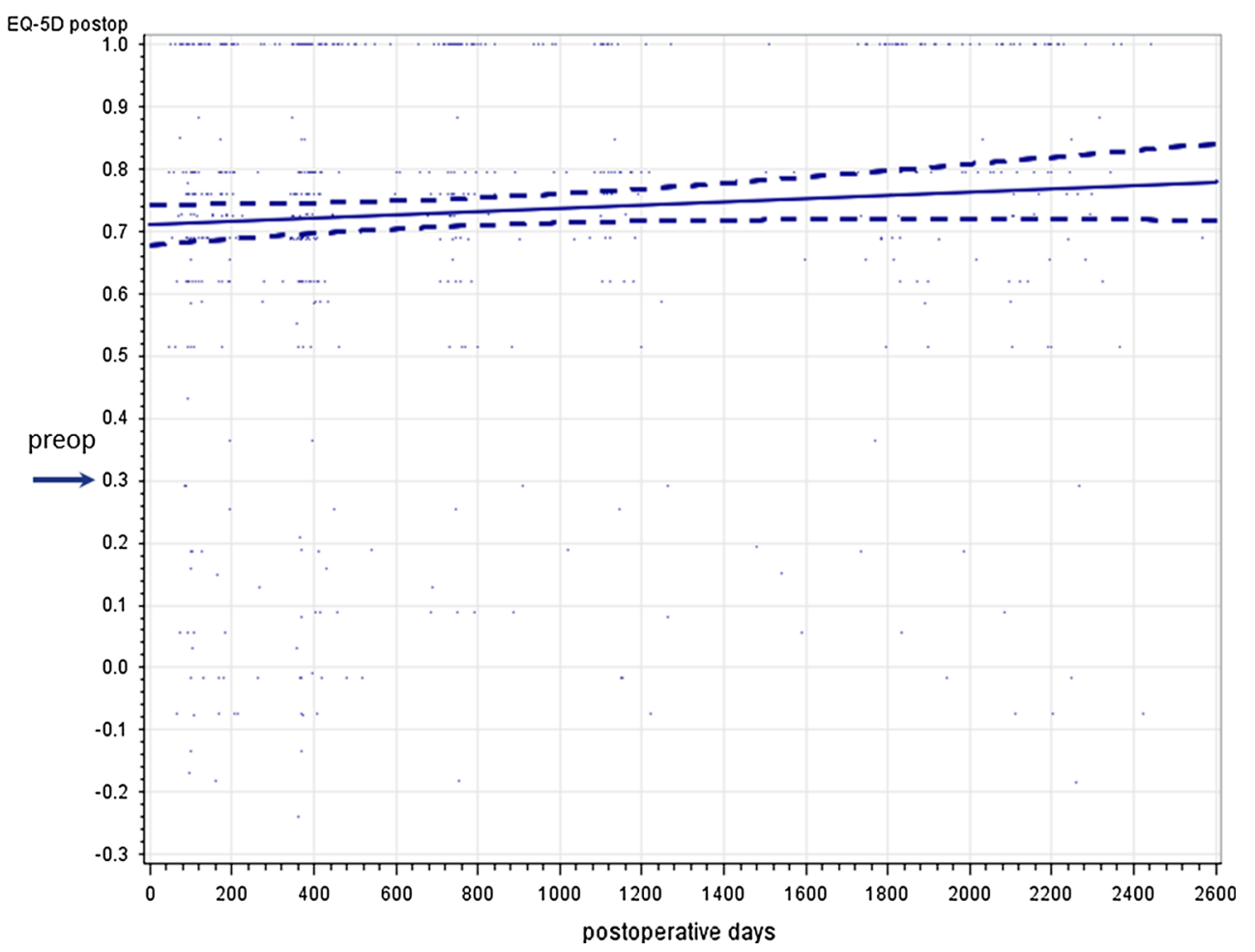

(2.6\%). In 4 out of 10 patients who were revised, an intraoperative complication was diagnosed. Those were the two patients with a vertebral fracture, one dura lesion and one subsidence of the prosthesis.

During follow-up, a new radiculopathy was diagnosed in 20 patients $(8.1 \%)$. Overall, in 26 patients $(10.5 \%)$ a new radiculopathy was recorded either early postoperative or during follow-ups. In three patients, a retrograde ejaculation (male patient-based rate $3 / 113=2.7 \%$ ) and in seven other patients a sympathectomy effect $(2.8 \%)$ were diagnosed. Forty-one other events were registered during follow-up in 31 patients (patient-based rate $12.5 \%$ ) and are shown in the Table 2.

Overall, the patient-based rate for an intra-, postoperative-, and follow-up complication including new radiculopathy, retrograde ejaculation and a sympathectomy effect was $23.4 \%(n=58)$.

During the five postoperative years, 11 patients $(4.4 \%)$ underwent a revision surgery or another related re-intervention. Ten revisions involved monosegmental patients $(5.2 \%)$ and one revision was performed in the caudal segment of a bisegmental patient (1.8\%). In 10 out of 11 revised patients one or several indications for a revision surgery were specified (Table 3): in five patients, a spondylodesis without prosthesis removal, in three patients prosthesis removal and spondylodesis, in one patient wound revision, in one patient decompression, and in one patient spondylodesis on a new caudal level were documented. The indication for the spondylodesis on a new caudal level was not specified. In two cases, a trauma was specified, whereas a very good postoperative course before the trauma was observed.

The average time to the first revision surgery was 33.4 months (range 1-79 months). A Kaplan-Meier survival analysis resulted in a cumulative survivorship of $90.4 \%$ over 5 years (95\% CI 80.3-95.4\%) (Fig. 4).

\section{Adjacent and distant segment degeneration}

Eleven patients $(11 / 103=10.7 \%)$ developed signs of ASD progression. Four out of 11 patients were treated on one segment (for monosegmental patients at 5-year followups $4 / 78=5.1 \%$ ) and 7 other patients on two segments (for bisegmental patients at 5-year follow-ups $7 / 25=28.0 \%$ ). All 11 patients had progression of the cranial adjacent segment.

Only 2 out of 95 patients with recorded data on distal segment degeneration had a progression of a distant segment degeneration $(2 / 95=2.1 \%)$, which was also located cranially. One progression of degeneration was documented in a monosegmental patient (for monosegmental patients at 5 years $1 / 72=1.4 \%$ ) and one in a bisegmental patient (for bisegmental patients at 5 years $1 / 23=4.4 \%$ ). One progression of distant segment degeneration occurred in a patient with an adjacent segment degeneration, who was a bisegmental patient. 


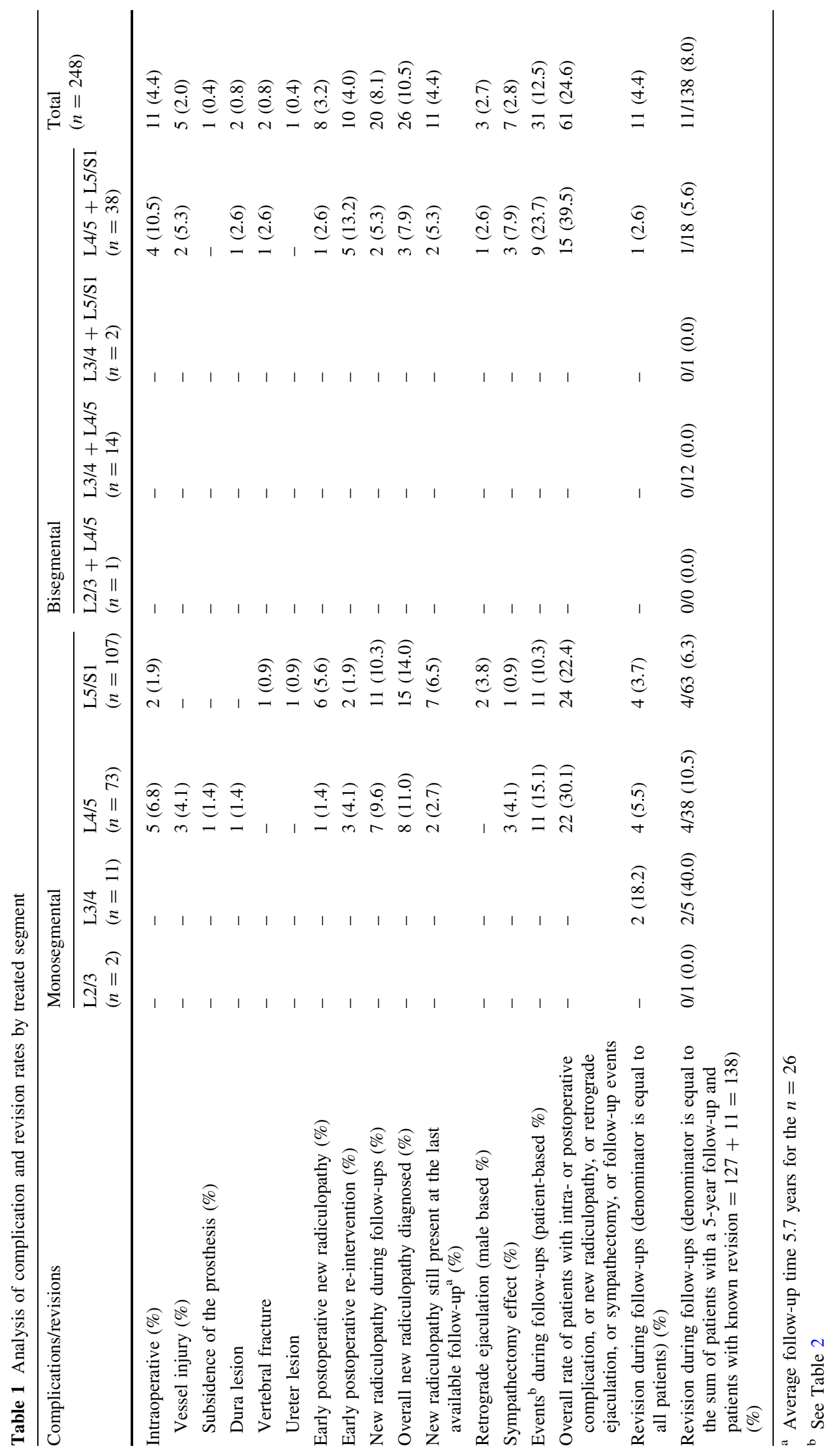


Table 2 Other events which were reported during five postoperative years

\begin{tabular}{lr}
\hline Event & $N$ \\
\hline Low back pain & 12 \\
Facet syndrome & 5 \\
Displacement of prosthesis & 2 \\
ISG syndrome & 3 \\
Neurological deficits in lower extremity & 3 \\
Endplate fracture & 2 \\
New leg pain unclear etiology & 2 \\
Wound healing disorder & 1 \\
Abdominal pain & 1 \\
Intestinal disorders & 1 \\
Discopathy with internal annulus rupture & 1 \\
N. genitofemoralis irritation & 1 \\
Neuropathic foot & 1 \\
Urination problem & 1 \\
Pain irradiation in the testicles region & 1 \\
Subileus signs & 1 \\
Small abdominal hernia & 1 \\
Muscular imbalance & 1 \\
Residual disc sequester & 1 \\
\hline
\end{tabular}

Comparison of patients with and without 5-year follow-ups

Table 4 demonstrates comparisons of different characteristics between the two patient groups. No significant differences were seen for patients' demographic characteristics. Postoperative back pain levels and quality of life scores were slightly but significantly worse in patients without long-term follow-ups (Table 4). These patients also had slightly but insignificantly higher back pain $(p=0.08)$ and lower quality of life $(p=0.10)$ at baseline. In the end, both groups benefited from a comparable and insignificantly different back pain relief and quality of life improvement. Also pre- and postoperative leg pain and leg pain relief were similar between the groups. There was an insignificant trend towards a higher rate for intraoperative complications in patients without long-term follow-ups. A significant difference in the overall proportion of patients with a newly diagnosed radiculopathy was seen, whereby patients with long-term follow-ups showed an about three times higher rate. Furthermore, proportions of events during follow-ups and overall combined complication rates were significantly higher in patients with long-term follow-up.

Table 3 Characteristics of performed revisions

\begin{tabular}{|c|c|c|c|c|c|c|}
\hline No. & Segment & Indications/symptoms & $\begin{array}{l}\text { Reoperations/complications } \\
\text { during index surgery }\end{array}$ & $\begin{array}{l}\text { Revision/re- } \\
\text { intervention type }\end{array}$ & $\begin{array}{l}\text { Disc } \\
\text { implant }\end{array}$ & $\begin{array}{l}\text { Spondylodesis } \\
\text { type }\end{array}$ \\
\hline 1 & $\mathrm{~L} 5 / \mathrm{S} 1$ & Persistent pain & Radiculopathy & Spondylodesis & In situ & Dorsal \\
\hline 2 & $\mathrm{~L} 4 / 5$ & $\begin{array}{l}\text { Implant dislocation, pain, facet joint } \\
\text { arthritis }\end{array}$ & None & Spondylodesis & In situ & Dorsal \\
\hline 3 & $\mathrm{~L} 3 / 4$ & n.s. & None & $\begin{array}{l}\text { Spondylodesis on } \\
\text { a new caudal } \\
\text { level }\end{array}$ & - & Ventral \\
\hline 4 & $\mathrm{~L} 4 / 5$ & Pain after a weight lifting trauma & None & Spondylodesis & In situ & Dorsal \\
\hline 5 & $\mathrm{~L} 4 / 5$ & $\begin{array}{l}\text { Implant dislocation, vertebral } \\
\text { fracture }\end{array}$ & None & Spondylodesis & Removed & Ventral \\
\hline 6 & $\mathrm{~L} 5 / \mathrm{S} 1$ & Wound healing disorder & None & Wound revision & - & - \\
\hline 7 & $\mathrm{~L} 4 / 5$ & Implant dislocation & None & Spondylodesis & Removed & Ventral \\
\hline 8 & $\mathrm{~L} 3 / 4$ & Persistent pain & None & Spondylodesis & In situ & Dorsal \\
\hline 9 & $\mathrm{~L} 5 / \mathrm{S} 1$ & $\begin{array}{l}\text { Radiculopathy, retrograde } \\
\text { ejaculation }\end{array}$ & $\begin{array}{l}\text { Dura lesion during primary } \\
\text { intervention, radiculopathy, } \\
\text { reoperation }\end{array}$ & Decompression & - & - \\
\hline 10 & $\mathrm{~L} 5 / \mathrm{S} 1$ & $\begin{array}{l}\text { Endplate fracture with bony } \\
\text { fragment, implant subsidence, } \\
\text { radiculopathy }\end{array}$ & Radiculopathy, reoperation & Spondylodesis & In situ & Dorsal \\
\hline 11 & $\begin{array}{l}\mathrm{L} 4 / \\
\quad 5+\mathrm{L} 5 / \\
\mathrm{S} 1\end{array}$ & Implant dislocation after a trauma & None & Spondylodesis & Removed & Ventral \\
\hline
\end{tabular}

n.s. not specified 


\section{Discussion}

The value of lumbar total disc arthroplasty in the variety of spinal surgical procedures is still debated although several

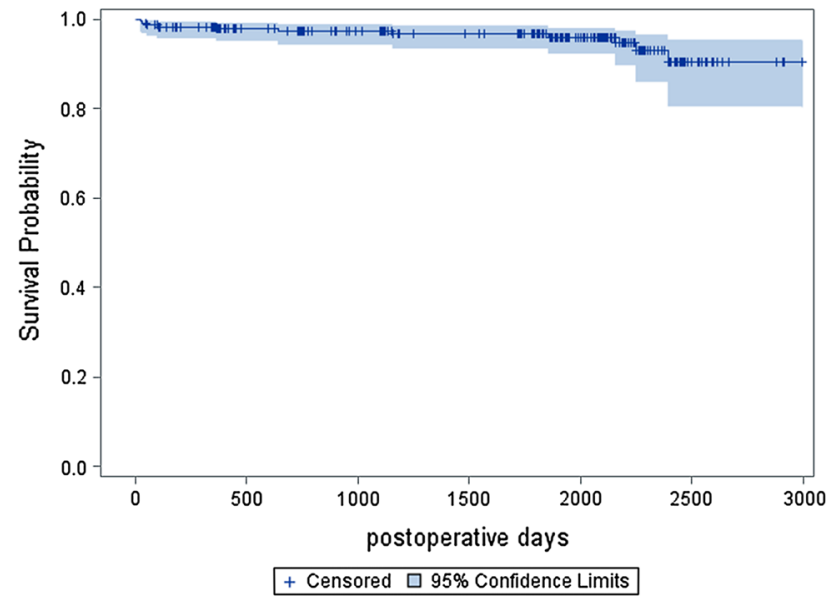

Fig. 4 Kaplan-Meier plot for the first revision or re-intervention of any type within five postoperative years (maximum 2,612 days) studies have proven the usefulness of this procedure, its non-inferiority or superiority to lumbar fusion in selected patients, and its safety regarding reoperations or complications [2, 3, 6, 7]. Also, cost-effectiveness compared with fusion was repeatedly shown [19-21]. However, evidence about long-term outcomes is still awaited.

An RCT with 5 years follow-up of 161 TDA patients with a Charité disc versus 75 patients with ALIF by Zigler et al. [2] showed that patients treated with either method maintained significant improvements until 5 years postoperative. The TDA group had significantly better improvements in ODI and SF-36 at some postoperative time points. The 2-year neurological success was also significantly higher in the TDA group. According to the authors, although TDA patients avoiding the stiffness of fusion and being more satisfied than fusion patients, both fusion and TDA were reasonable surgical options in this specific patient population. Similarly, the RCT by Guyer et al. [3] did not find significant differences between TDA and ALIF, except for a statistically greater rate of part- and fulltime employment and a statistically lower rate of long-term

Table 4 Comparison of patients with and without 5-year follow-ups

\begin{tabular}{|c|c|c|c|}
\hline Patient characteristics & $\begin{array}{l}\text { Patients with a } \\
\text { 5-year follow-up }\end{array}$ & $\begin{array}{l}\text { Patients without a } \\
\text { 5-year follow-up }\end{array}$ & $\begin{array}{l}\text { Comparison } \\
(p \text { value })\end{array}$ \\
\hline$N$ & 127 & 121 & - \\
\hline Mean age (SD) & $41.6(8.7)$ & $42.9(7.6)$ & 0.21 \\
\hline Age range & $19-65$ & $25-62$ & - \\
\hline Female $(\%)$ & 59.8 & 50.0 & 0.10 \\
\hline Bisegmental patients $(\%)$ & 23.6 & 20.7 & 0.57 \\
\hline $\mathrm{L} 4 / 5(\%)$ & 26.8 & 32.2 & 0.52 \\
\hline $\mathrm{L} 5 / \mathrm{S} 1(\%)$ & 13.4 & 17.4 & \\
\hline $\mathrm{L} 4 / 5+\mathrm{L} 5 / \mathrm{S} 1(\%)$ & 46.5 & 39.7 & \\
\hline Other treated segments $(\%)$ & 13.4 & 10.7 & \\
\hline Time to last available follow-up in months (SD) & $64.9(10.8)$ & $19.9(13.7)$ & - \\
\hline Preop back pain (SD) & $70(21)$ & $74(20)$ & 0.08 \\
\hline Back pain at last available follow-up (SD) & $29(28)$ & $39(30)$ & 0.011 \\
\hline Back pain relief (SD) & $41(32)$ & $35(34)$ & 0.19 \\
\hline Preop leg pain (SD) & $53(28)$ & $57(29)$ & 0.20 \\
\hline Leg pain at last available follow-up (SD) & $23(29)$ & $25(28)$ & 0.36 \\
\hline Leg pain relief $(\mathrm{SD})$ & $30(35)$ & $32(35)$ & 0.84 \\
\hline Preop EuroQoL-5D score (SD) & $0.31(0.34)$ & $0.25(0.32)$ & 0.10 \\
\hline EuroQoL-5D score at last available follow-up (SD) & $0.77(0.27)$ & $0.64(0.33)$ & $<0.001$ \\
\hline EuroQoL-5D score improvement (SD) & $0.46(0.37)$ & $0.39(0.41)$ & 0.19 \\
\hline Intraoperative complications $(\%)$ & 2.4 & 6.6 & 0.10 \\
\hline Overall proportion of newly diagnosed radiculopathy $(\%)$ & 15.8 & 5.0 & 0.006 \\
\hline Events during follow-ups (patient-based \%) & 16.5 & 8.3 & 0.049 \\
\hline $\begin{array}{l}\text { Overall rate of patients with intra- or postoperative complication, or new } \\
\text { radiculopathy, or retrograde ejaculation, or sympathectomy, or follow-up events }\end{array}$ & 30.7 & 18.2 & 0.022 \\
\hline
\end{tabular}

All categorical characteristics were compared using the Chi-square test and all continuous characteristics using the Wilcoxon rank-sum test SD standard deviation 
disability in TDA patients. A recent RCT of TDA versus posterior and posterolateral fusion techniques with highly selected patients showed significantly better results for most of the outcomes in favour of TDA patients [7]. However, posterior fusion is a less suitable comparator for TDA.

Pain relief, medication consumption and quality of life

In the report by Van de Kelft et al. [8] of 50 consecutive cases with the Maverick disc, back pain levels dropped from 7.4 preoperatively to 2.6 at the 4 -year follow-up. Blondel et al. [12] reported back pain relief from 7.2 to 2.4 and leg pain relief from 6.4 to 2.2 between baseline and 2-year follow-up in 221 patients with the ProDisc-L disc. In the RCT by Guyer et al. [3], preoperative back pain was about 70 VAS points and postoperative back pain was long lasting at 30 points until 5 years postoperative. The clinical outcome series by Park et al. of patients with ProDisc-L showed pain relief from 7.8 preoperative to 2.3 postoperative at the 5-year follow-up. The RCT by Zigler et al. on patients with a Charité disc reported pain relief from 74.9 to 40 VAS points at 5 years after surgery. All these reports are well corresponding with the pain relief observed in the SWISSspine registry, which was 72 VAS points at baseline and 28 points at the 5-year follow-up. Both back and leg pain alleviation seem to last without notable deterioration until the fifth postoperative year. This effect was reflected in significantly reduced pain killer consumption and significantly improved quality of life. Moreover, the quality of life was further improving over the postoperative period, as was the consumption of NSAIDs.

\section{Adjacent and distant segment degeneration}

In the RCT by Zigler et al. [22], $9.2 \%$ of the TDA patients and $28.6 \%$ of the fusion patients showed degenerative changes in the adjacent segments. Fused patients had a three times higher likelihood to have an ASD change. It is noteworthy, however, that only $76.4 \%$ of the TDA patients and $57.3 \%$ of the fusion patients had complete 5-year radiographic follow-up data. The authors also reported that $1.9 \%$ of the TDA group and $4.0 \%$ of the circumferential fusion group had adjacent-level surgery during the follow-up period, which was not significantly different [22]. David [10] reported an adjacent level surgery in $2.8 \%$ after 10 years in 106 patients with Charité discs. We observed $10.7 \%$ adjacent and $2.1 \%$ distant segment degeneration. Both adjacent and distant segment degenerations in our cohort occurred only in cranial segments. Our ASD proportion corresponds to the results reported by Zigler et al. [2]. None of the indications for revision surgery in our cohort was based on
ASD, which some authors would therefore only consider as adjacent segment degeneration, but not as true "disease". However, for one revision on a new caudal level the indication was not specified.

Segmental mobility and ossification

The ROM after TDA using Charité discs remained roughly constant between the 2-year $\left(7.7^{\circ}\right)$ and 5 -year $\left(7.2^{\circ}\right)$ time points in the RCT by Zigler et al. [2]. In their report, $91.9 \%$ of the TDA patients had preserved a normal segmental ROM at 5 years. The report by Gornet et al. [4] of patients with Maverick discs showed an average ROM of $9.4^{\circ}$ at 1 year and $9.5^{\circ}$ at 2 years postoperative. Van der Kelft et al. [8] studied 4-year results of Maverick discs and reported average ROM between $11^{\circ}$ and $13^{\circ}$ on L4/5 and L5/S1 segments, respectively. Two patients treated on the L3/4 segment had an average $23^{\circ}$ ROM. In the RCT by Berg et al. [23], 88.5\% of segments treated with Maverick, ProDisc-L or Charite were mobile at the 2-year follow-up. The authors had regarded a L3/4 and L4/5 segmental ROM of $\leq 2^{\circ}$ as immobile ( $44.8 \%$ of the studied segments), and for L5/S1 a ROM of $\leq 4.5^{\circ}$ for L5/S1 segment (55.2\% of the studied segments). Guyer et al. [3] reported $84.5 \%$ of lumbar TDA cases with the Charite disc having ROM $>3^{\circ}$ at the 5-year follow-up. According to our observations $87.0 \%$ of discs had a ROM $\geq 2^{\circ}$, and $74.0 \%$ a ROM $>3^{\circ}$ at 5 years. The average ROM of the mobile segments was $9.8^{\circ}$, which is rather in accordance with the published numbers.

The evidence about HO after lumbar TDA is sparse. According to the 5-year results of Guyer et al. [3], $18.9 \%$ of Charité discs had HOs that would impact motion. The authors used a six-point scale as a combined classification system adapted from Nathan and McAfee. $16.7 \%$ of our segments had McAfee grade III HO defined as blocking the range of motion of the vertebral endplates. Additionally, $27.2 \%$ of segments were classified as grade II with a potentially affected motion. Other authors reported much lower ossification rates at different postoperative time points; however, classifications other than McAfee were used [10, 24-26]. Influence of HO on clinical outcome was not yet confirmed in any of the reports.

The surgeon-based $13.5 \%$ rate of osteophytes was comparable with the independently assessed $16.7 \%$ of grade III HO in the current cohort.

A poor correlation between clinical outcome and position of the prosthesis was recently reported by Boss et al. [27] in his cohort with 2-year follow-ups from the SWISSspine registry. Most of the patients reached a very good clinical outcome. However, suboptimally placed devices appear to cause significantly more neurological symptoms [27]. 


\section{Complications and revisions}

Overall observed complication and event rate was $24.6 \%$ during the first five postoperative years, which is a rather high patient-based rate. However, one should note that many observed complications and events were of a transient character reported only once during multiple followups such as low back pain or abdominal pain, muscular imbalance and new leg pain of unclear etiology. A recent meta-analysis of TDA versus any other intervention by Wei et al. [28] counted major complications such as device failures necessitating reoperations, revisions, removals, major vessel injury, neurologic damage, nerve root injury, death, etc., and reported a $5.8 \%$ pooled complication rate for five trials and 1,525 patients. Many complications, which were registered during follow-ups in SWISSspine, such as vessel injury, dura lesion, urination problem, ureter lesion, subileus signs, abdominal hernia, abdominal pain, wound healing disorder or intestinal disorders can be related to the surgical approach, which is in fact the standard anterior approach to the lumbar spine. The potentially implant-related complications were two intraoperative vertebral fractures, one intraoperative implant subsidence and two endplate fractures during follow-up without surgical consequences. Moreover, newly diagnosed radiculopathy in $10.5 \%$ and neurological deficits are also rather TDA-related complications. Newly diagnosed radiculopathy was transient in $6.1 \%$ of the patients, but remained present in another $4.4 \%$ at the last available follow-up. It seems that radicular pain was intermittent in those patients. Published figures on new radiculopathy are rare, unfortunately. Van Ooij et al. [29] described new radiculopathy as a late complication in $3.7 \%$ of his 27 patients with an average of 4.4 years of follow-up. In his retrospective analysis, McAffe et al. [30] described 589 discs with a $2.4 \%$ rate for iatrogenic neurologic complications at a minimum 2-year follow-up. In his report of the long-term results of a single surgeon experience in the SWISSspine registry, Markwalder et al. [31] reported one new radiculopathy in 14 studied TDA patients $(7.1 \%)$, which was transient during 6.5 postoperative years. In the analysis by Boss et al. [27], which included 46 patients, neurological radicular deficits disappeared in $72.7 \%$, improved in $9.1 \%$, but remained unchanged in $18.2 \%$ after 2 years. The potential source of persisting or new radiculopathy may be a recurrent disc herniation with a sequestered fragment of the annulus, and an incomplete disc removal [12, 29]. Furthermore, a restoration of disc height may potentially cause increased traction of nerve roots with or without vascular changes that can be similar to an arterial ischemia [12]. Accordingly, in the randomized controlled trial by Gornet et al. [4] $48 \%(n=11)$ of the reoperations after TDA were decompression procedures to relieve persistent postoperative radicular symptoms.

The overall rate for revisions in the registry was $4.4 \%$. A similar rate of $5.2 \%$ after lumbar TDA was reported in the meta-analysis by Wei et al. [28]. In the US, studies by Zigler et al. [2, 30] and McAfee et al. [30] reported 8.0 and $8.8 \%$ revision rates, respectively. If calculating our revision rate based on patients with 5-year results and patients with known revision data, we find an $8.0 \%$ rate.

Ross et al. [32] reported a cumulative survival rate of $90 \%$ at 8.4 years in 160 patients with a Charité disc when implant removal was the end point of the analysis. This rate seems to be quite close to our $90.4 \%$ at 5 years. McAfee et al. [30] reported an even higher survival rate of $97 \%$ after 5 years for the Charite disc in 98 consecutive cases. Further long-term surveillance of TDA revisions is certainly required and should ideally be conducted in national registries such as SWISSspine.

Regarding mode of failure, four implant dislocations were seen in 11 revised patients, which should be regarded as an implant-related failure. Persistent or new back pain in three patients, radiculopathy in two patients, vertebral fracture in two patients and wound healing disorder in one patient were seen otherwise. Those complications are known revision causes after lumbar TDA [33]. During spondylodesis revision surgery, the artificial disc was removed in three cases and remained in situ in five cases. McAfee et al. [30] reported similar rates for implant removal and non-removal in their 52 revision surgeries with a slightly higher tendency of leaving implants in situ.

In his meta-analysis, Wei et al. [28] showed TDA to be safe and effective and suggested adopting the therapy on a large scale.

The numbers of individual types of complications had relatively low statistical power after stratification by treated segment; however, in a descriptive analysis a trend for increasing incidence of overall adverse events from a monosegmental L5/S1 (22.4 \%) over monosegmental L4/5 $(30.1 \%)$ to a bisegmental L4-S1 (39.5\%) surgery becomes noticeable. A similar trend was also observed for early postoperative re-intervention and sympathectomy effect. The vascular injuries were all found in mono- and bi-segmental cases involving L4/5 [34]. Similarly, all retrograde ejaculations occurred in mono- and bi-segmental cases involving L5/S1, which was also reported by Lindley et al. [35].

Revision rates were relatively more frequent on L3/4, followed by L4/5, L5/S1 and then by bisegmental surgery on L4-S1. One of the two patients with a revision of the L3/4 segment underwent a spondylodesis on a new caudal level as revision surgery. The anatomical characteristics of the two most distal lumbar segments, proximity of the bifurcation of vessels and other anatomical structures and 
at the same time the highest load on the prosthesis are likely explanations for these findings.

Mayer and Siepe [36] compared the history of fusion and TDA and criticized the fact that despite a long acceptance for fusion as the gold standard without comparative and controlled evidence, despite high reoperation and complications rates and adjacent segment alterations, no reconsideration of this therapeutic option has taken place. A possible reason may be the fact that for many years, fusion was the only option surgeons had for the treatment of degenerative low back pain. However, the worldwide introduction of lumbar TDA since the end of the 1990s has produced paradoxical, controversial, and occasionally irrational reactions amongst surgeons, regulatory institutions, health insurance companies, and other health care providers [36].

\section{Limitations and strengths}

Some limitations of the study require mention. No direct comparator was included in the SWISSspine registry; thus, a comparative evidence judgment can only be made by comparing the results to the published literature or other indirect comparators [16]. A complete documentation of a comparator procedure like fusion or non-surgical treatment in a national registry would need additional and substantial administrative and financial efforts, which were considered as not feasible by the stakeholders of the registry. A strength of the registry cohort, however, is the generalizability of its outcomes since it represents real-life clinical practice with high external validity, at least on a national level. The few currently existing spine registries are expected to deliver further generalizable results on spinal treatments [37-39]. A strength of this particular report is that it presents both survival, radiological and clinical data.

Being an observational unmonitored study, a potential underreporting of surgeon-based parameters such as complications and revisions cannot be completely excluded. All surgeons participating in the documentation are certified by the Swiss Spine Society for conducting lumbar TDA surgery, which means that they have proven the essential training and qualifications and have agreed to accurately document the interventions. The accordance between the surgeon-based and independent measurements of ROM and HO shows, however, at least a conscientious documentation of segmental mobility and heterotopic ossifications. An audit or any other control mechanism in a national registry would need strong financial and organizational resources and was considered as not feasible by the SWISSspine stakeholders. This remains a limitation for the findings from the SWISSspine registry.

The 5-year follow-up rate in the analysis was $51.2 \%$. The follow-up rates in long-term clinical studies in the US vary from $43.4 \%$ in the Guyer 2009 study of the Charite disc [3], to $68.3 \%$ in the Weinstein 2009 fusion/SPORT study [40] and $81.8 \%$ in the RCT comparison of TDA versus fusion by Zigler et al. [2]. The execution of the 5 -year follow-ups in a national registry is, however, a complex endeavour. Several administrative patient and surgeon related difficulties were already reported for the cervical cohort [38]. The registry patients who were lost to follow-up may have potentially introduced a selection bias. Comparison of patients with and without 5-year follow-ups showed that the patient groups were not significantly different regarding patient demographics, pain relief and quality of life improvement, but different regarding the levels of back pain and of quality of life at the last available follow-up. Patients lost to the 5-year follow-up had slightly but significantly higher postoperative back pain and lower QoL levels. One has to note, however, that the patients lost to follow-up underwent surgery with worse baseline values for these outcomes. The worse baseline values in patients without long-term follow-ups and comparable pain relief and quality of life improvement in both patient groups reduce the meaning of the significantly different postoperative back pain and quality of life levels as a pro-selection bias argument. Furthermore, quality of life tends to further improve over time as shown in Fig. 3. The average 64.9- and 19.9-month follow-up intervals in the groups with and without 5-year follow-up may at least partially explain the difference in quality of life levels. On the other hand, new postoperative radiculopathy and other undesired events were significantly higher in the group with 5 years follow-up, which may at least partially be a function of time. Given these facts, a clear evidence for selection bias does not become obvious, but the follow-up rate certainly makes it possible and may have introduced slightly advantageous results in favour of TDA.

The overall results of our study still seem to be in accordance with the published literature and with the shortterm results in the registry. Ten-year follow-ups of the same cohort are planned in the near future. Furthermore, only $68.5 \%$ of patients underwent a radiological examination at 5 years. Patients were reluctant to undertake radiological examinations mostly due to the out-of-pocket expenses, if a deductible is part of the insurance contract, which is very common in Switzerland. In addition, freedom of symptoms makes patients accept the radiographic part of the follow-up even less.

The studied registry cohort represents the first 248 patients, which were documented since the registry launch and termination of the moratorium for TDA in Switzerland. It can be speculated that further technical and instrumental developments and continuously growing knowledge on appropriate patient selection [41-43] should further improve todays' reported outcomes, but also increase patients' treatment expectations. 
The model of a governmentally mandated nationwide spine registry could, if adopted in a quality controlled and monitored way, not only provide evidence-based information with a sufficient internal and a high external validity; it could also generate new knowledge much faster and in a more cost-efficient manner compared with the currently non-harmonized individual efforts in clinical study settings, HTAs, post-market surveillance programs, etc. The same (registry based) dataset could be used for various purposes and stakeholders, and they could all jointly participate in organizing, administering and financing such an endeavor. The "platinum version" of such a model would then be the expansion into an international registry or at least a registry cooperation, similar to Eurospine's Spine Tango [37] or European Federation of National Associations of Orthopaedics and Traumatology (EFORT) and International Society of Arthroplasty Registries (ISAR).

\section{Conclusions}

Five-year follow-up results of lumbar TDA in the SWISSspine registry demonstrated significant and long-lasting back and leg pain relief along with reduction of pain killer consumption and improvement of quality of life. The vast majority of segments remained mobile, although $43.9 \%$ of them showed heterotopic ossifications, which could at least potentially affect segmental motion. The procedure appeared sufficiently safe, though surgeons have to be aware of a list of potential adverse events. Long-term observation of revision rates and adjacent segment disease is required for further evidence generation.

\footnotetext{
Acknowledgments The authors are thankful to the SWISSspine registry group who made this research possible by populating the database with their valuable and much appreciated entries. Among others, data of the following colleagues were used in the study: Etter C $(n=26)$, Bärlocher $\mathrm{C}(n=24)$, Sgier $\mathrm{F}(n=24)$, Huber $\mathrm{J}(n=17)$, Otten $\mathrm{P}(n=15)$, Heini $\mathrm{P}(n=13)$, Hausmann $\mathrm{O}(n=12)$, Maestretti $\mathrm{G}(n=11), \operatorname{Baur} \mathrm{M}(n=9), \operatorname{Porchet} \mathrm{F}(n=9)$, Markwalder T $(n=8)$, Renella R $(n=8)$, Schaeren S $(n=6)$, Self T $(n=6)$, Schwarzenbach $\mathrm{O}(n=5)$, Kast E $(n=4)$, Kleinstück F $(n=4)$, Lattig F $(n=4)$, Min $\mathrm{K}(n=4)$, Schizas C $(n=4)$, Berlemann $\mathrm{U}(n=3)$, Grob D $(n=3)$, Hasdemir $\mathrm{M}(n=3)$, Marchesi $\mathrm{D}(n=3)$, Aebi $\mathrm{M}(n=2)$, Binggeli $\mathrm{R}$ $(n=2)$, Boscherini $\mathrm{D}(n=2)$, Favre $\mathrm{J}(n=2)$, Forster T $(n=2)$, Jeanneret $\mathrm{B}(n=2)$, Moulin $\mathrm{P}(n=2)$, Tessitore $\mathrm{E}(n=2)$, Boos $\mathrm{N}$ $(n=1)$, Cathrein $\mathrm{P}(n=1)$, Kroeber $\mathrm{M}(n=1)$, Payer $\mathrm{M}(n=1)$, Ramadan A $(n=1)$, Stoll T $(n=1)$, Wernli F $(n=1)$. Funded by the AO Foundation start-up-grant S-10-41A.
}

Conflict of interest None.

\section{References}

1. Mayer HM, Korge A (2002) Non-fusion technology in degenerative lumbar spinal disorders: facts, questions, challenges. Eur Spine J 11(Suppl 2):S85-S91
2. Zigler JE, Delamarter RB (2012) Five-year results of the prospective, randomized, multicenter, Food and Drug Administration investigational device exemption study of the ProDisc-L total disc replacement versus circumferential arthrodesis for the treatment of single-level degenerative disc disease. J Neurosurg Spine 17:493-501

3. Guyer RD, McAfee PC, Banco RJ, Bitan FD, Cappuccino A, Geisler FH, Hochschuler SH, Holt RT, Jenis LG, Majd ME, Regan JJ, Tromanhauser SG, Wong DC, Blumenthal SL (2009) Prospective, randomized, multicenter Food and Drug Administration investigational device exemption study of lumbar total disc replacement with the CHARITE artificial disc versus lumbar fusion: five-year follow-up. Spine J 9:374-386

4. Gornet MF, Burkus JK, Dryer RF, Peloza JH (2011) Lumbar disc arthroplasty with Maverick disc versus stand-alone interbody fusion: a prospective, randomized, controlled, multicenter investigational device exemption trial. Spine (Phila $\mathrm{Pa}$ 1976) 36:E1600-E1611

5. Aghayev E, Elfering A, Schizas C, Mannion AF, Group SWR (2014) Factor analysis of the North American Spine Society outcome assessment instrument: a study based on a spine registry of patients treated with lumbar and cervical disc arthroplasty. Spine J 14(6):916-924. doi:10.1016/j.spinee.2013.07.446

6. McAfee PC, Cunningham B, Holsapple G, Adams K, Blumenthal S, Guyer RD, Dmietriev A, Maxwell JH, Regan JJ, Isaza J (2005) A prospective, randomized, multicenter Food and Drug Administration investigational device exemption study of lumbar total disc replacement with the CHARITE artificial disc versus lumbar fusion: part II: evaluation of radiographic outcomes and correlation of surgical technique accuracy with clinical outcomes. Spine (Phila Pa 1976) 30:1576-1583 (discussion E1388-1590)

7. Skold C, Tropp H, Berg S (2013) Five-year follow-up of total disc replacement compared to fusion: a randomized controlled trial. Eur Spine J 22(10):2288-2295

8. Van de Kelft E, Verguts L (2012) Clinical outcome of monosegmental total disc replacement for lumbar disc disease with ball-and-socket prosthesis (Maverick): prospective study with four-year follow-up. World Neurosurg 78:355-363

9. Putzier M, Funk JF, Schneider SV, Gross C, Tohtz SW, Khodadadyan-Klostermann C, Perka C, Kandziora F (2006) Charite total disc replacement-clinical and radiographical results after an average follow-up of 17 years. Eur Spine J 15:183-195

10. David T (2007) Long-term results of one-level lumbar arthroplasty: minimum 10-year follow-up of the CHARITE artificial disc in 106 patients. Spine (Phila Pa 1976) 32:661-666

11. Meir AR, Freeman BJ, Fraser RD, Fowler SM (2013) Ten-year survival and clinical outcome of the AcroFlex lumbar disc replacement for the treatment of symptomatic disc degeneration. Spine J 13:13-21

12. Blondel B, Tropiano P, Gaudart J, Marnay T (2011) Clinical results of total lumbar disc replacement regarding various aetiologies of the disc degeneration: a study with a 2-year minimal follow-up. Spine (Phila Pa 1976) 36:E313-E319

13. Schluessmann E, Diel P, Aghayev E, Zweig T, Moulin P, Roder C (2009) SWISSspine: a nationwide registry for health technology assessment of lumbar disc prostheses. Eur Spine J 18:851-861

14. Zweig T, Aghayev E, Melloh M, Dietrich D, Dietrich D, Roder C, SWISSspine Registry Group (2012) Influence of preoperative leg pain and radiculopathy on outcomes in mono-segmental lumbar total disc replacement: results from a nationwide registry. Eur Spine J 21(Suppl 6):S729-S736

15. Aghayev E, Roder C, Zweig T, Etter C, Schwarzenbach O (2010) Benchmarking in the SWISSspine registry: results of 52 Dynardi lumbar total disc replacements compared with the data pool of 431 other lumbar disc prostheses. Eur Spine J 19(12):2190-2199 
16. Aghayev E, Henning J, Munting E, Diel P, Moulin P, Roder C, Swissspine, Spine Tango Registry Groups (2012) Comparative effectiveness research across two spine registries. Eur Spine J 21:1640-1647

17. IEFM (2014) University of Bern. www.memdoc.org

18. McAfee PC, Cunningham BW, Devine J, Williams E, Yu-Yahiro J (2003) Classification of heterotopic ossification (HO) in artificial disk replacement. J Spinal Disord Tech 16:384-389

19. Guyer RD, Tromanhauser SG, Regan JJ (2007) An economic model of one-level lumbar arthroplasty versus fusion. Spine J 7:558-562

20. Kurtz SM, Lau E, Ianuzzi A, Schmier J, Todd L, Isaza J, Albert TJ (2010) National revision burden for lumbar total disc replacement in the United States: epidemiologic and economic perspectives. Spine (Phila Pa 1976) 35(6):690-696. doi:10.1097/ BRS.0b013e3181d0fabb

21. Levin DA, Bendo JA, Quirno M, Errico T, Goldstein J, Spivak J (2007) Comparative charge analysis of one- and two-level lumbar total disc arthroplasty versus circumferential lumbar fusion. Spine (Phila Pa 1976) 32:2905-2909

22. Zigler JE, Glenn J, Delamarter RB (2012) Five-year adjacentlevel degenerative changes in patients with single-level disease treated using lumbar total disc replacement with ProDisc-L versus circumferential fusion. J Neurosurg Spine 17:504-511

23. Berg S, Tropp HT, Leivseth G (2011) Disc height and motion patterns in the lumbar spine in patients operated with total disc replacement or fusion for discogenic back pain. Results from a randomized controlled trial. Spine J 11:991-998

24. Park SJ, Kang KJ, Shin SK, Chung SS, Lee CS (2011) Heterotopic ossification following lumbar total disc replacement. Int Orthop 35:1197-1201

25. Lemaire JP, Carrier H, el Sariali H, Skalli W, Lavaste F (2005) Clinical and radiological outcomes with the Charite artificial disc: a 10-year minimum follow-up. J Spinal Disord Tech 18:353-359

26. Tortolani PJ, Cunningham BW, Eng M, McAfee PC, Holsapple GA, Adams KA (2007) Prevalence of heterotopic ossification following total disc replacement. A prospective, randomized study of two hundred and seventy-six patients. JBJS Am $89: 82-88$

27. Boss OL, Tomasi SO, Baurle B, Sgier F, Hausmann ON (2013) Lumbar total disc replacement: correlation of clinical outcome and radiological parameters. Acta Neurochir (Wien) 155(10):1923-1930

28. Wei J, Song Y, Sun L, Lv C (2013) Comparison of artificial total disc replacement versus fusion for lumbar degenerative disc disease: a meta-analysis of randomized controlled trials. Int Orthop 37(7):1315-1325

29. van Ooij A, Oner FC, Verbout AJ (2003) Complications of artificial disc replacement: a report of 27 patients with the SB Charite disc. J Spinal Disord Tech 16:369-383

30. McAfee PC, Geisler FH, Saiedy SS, Moore SV, Regan JJ, Guyer RD, Blumenthal SL, Fedder IL, Tortolani PJ, Cunningham B (2006) Revisability of the CHARITE artificial disc replacement: analysis of 688 patients enrolled in the U.S. IDE study of the CHARITE artificial disc. Spine (Phila Pa 1976) 31:1217-1226

31. Markwalder TM, Wenger M, Marbacher S (2011) A 6.5-year follow-up of 14 patients who underwent ProDisc total disc arthroplasty for combined long-standing degenerative lumbar disc disease and recent disc herniation. J Clin Neurosci 18(12):1677-1681

32. Ross R, Mirza AH, Norris HE, Khatri M (2007) Survival and clinical outcome of SB Charite III disc replacement for back pain. JBJS Br 89:785-789

33. Punt IM, Visser VM, van Rhijn LW, Kurtz SM, Antonis J, Schurink GW, van Ooij A (2008) Complications and reoperations of the SB Charite lumbar disc prosthesis: experience in 75 patients. Eur Spine J 17:36-43

34. Inamasu J, Guiot BH (2006) Vascular injury and complication in neurosurgical spine surgery. Acta Neurochir (Wien) 148(4):375-387

35. Lindley EM, McBeth ZL, Henry SE, Cooley R, Burger EL, Cain CM, Patel VV (2012) Retrograde ejaculation after anterior lumbar spine surgery. Spine (Phila Pa 1976) 37:1785-1789

36. Mayer HM, Siepe CJ (2011) Prosthetic total disk replacementcan we learn from total hip replacement? Orthop Clin N Am 42(4):543-554

37. Neukamp M, Perler G, Pigott T, Munting E, Aebi M, Roder C (2013) Spine Tango annual report 2012. Eur Spine J. doi:10. 1007/s00586-013-2943-x (in press)

38. Aghayev E, Barlocher C, Sgier F, Hasdemir M, Steinsiepe KF, Wernli F, Porchet F, Hausmann O, Ramadan A, Maestretti G, Ebeling U, Neukamp M, Roder C (2013) Five-year results of cervical disc prostheses in the SWISSspine registry. Eur Spine $\mathrm{J}$ 22(8):1723-1730

39. Breakwell LM (2013) Understanding the need for spinal registries: Lee Breakwell reviews the importance of registries in spinal research and explains why British Association of Spinal Surgeons (BASS) has decided to set up its own registry. Eur Spine J 22(1):S5-S6. doi:10.1007//s00586-013-2666-Z

40. Weinstein JN, Lurie JD, Tosteson TD, Zhao W, Blood EA, Tosteson AN, Birkmeyer N, Herkowitz H, Longley M, Lenke L, Emery S, Hu SS (2009) Surgical compared with nonoperative treatment for lumbar degenerative spondylolisthesis. Four-year results in the Spine Patient Outcomes Research Trial (SPORT) randomized and observational cohorts. JBJS Am 91:1295-1304

41. Rohlmann A, Lauterborn S, Dreischarf M, Schmidt H, Putzier M, Strube P, Zander T (2013) Parameters influencing the outcome after total disc replacement at the lumbosacral junction. Part 1: misalignment of the vertebrae adjacent to a total disc replacement affects the facet joint and facet capsule forces in a probabilistic finite element analysis. Eur Spine J 22(10):2271-2278

42. Zweig T, Hemmeler C, Aghayev E, Melloh M, Etter C, Roder C (2011) Influence of preoperative nucleus pulposus status and radiculopathy on outcomes in mono-segmental lumbar total disc replacement: results from a nationwide registry. BMC Musculoskelet Disord 12:275

43. Diel P, Reuss W, Aghayev E, Moulin P, Roder C, Group SWR (2010) SWISSspine-a nationwide health technology assessment registry for balloon kyphoplasty: methodology and first results. Spine J 10:961-971 